\title{
Nudging Public Employees Through Descriptive Social Norms in Healthcare Organizations
}

\section{Research Article}

Nicola Belle is an Assistant Professor at

Abstract: We draw on the focus theory of normative conduct and nudge theory to experimentally test the effect of descriptive social norms on desired behaviors that public employees may engage in at suboptimal levels, namely, vaccination and help-seeking. Through a series of framed randomized controlled trials with 19,984 public healthcare professionals, we demonstrate that descriptive norms — doing what the majority of others do - trigger conformity. Specifically, employees are more likely to get a flu shot and advocate vaccination when knowing that the majority of their colleagues get vaccinated against the seasonal influenza compared to when most colleagues do not. Similarly, the probability of making help requests on the job is noticeably higher when asking colleagues for advice is the norm rather than not. We discuss the theoretical and practical implications of these experiments for scholars and policy makers interested in predictably altering high-stakes behaviors among public employees through low-powered incentives.

\section{Evidence for Practice}

- Public organizations and their managers can leverage social norms to fuel desired behaviors that employees may otherwise engage in at suboptimal levels.

- Public organizations with high vaccination coverage rates can promote vaccination by informing their employees that the majority of their colleagues get the flu shot.

- Public organizations with low vaccination coverage rates must implement interventions to increase vaccination coverage before they can take advantage of the effect of descriptive social norms.

- Explicitly communicating that asking colleagues for help is a desirable social norm can foster widespread adoption of this behavior, which in turn can trigger helping at work.

If choice architects want to shift behavior and to do so with a nudge, they might simply inform people about what other people are doing.

Thaler and Sunstein (2008)

$\mathrm{V}$ accination has proven to be a highly costeffective means of improving world health, yet "every year throughout the world... two to three million people die from diseases that can be prevented with vaccines" (Banerjee et al., 2010, 1). Seasonal influenza alone, for example, causes up to 650,000 deaths (Organization for Economic Cooperation and Development, 2019). According to the World Health Organization (WHO), "health-care workers are an important priority group for influenza vaccination [and their immunization] should be considered part of a broader infection control policy" (WHO, 2012, 475). Therefore, promoting vaccination among their workers should be a priority for public healthcare organizations. However, this is easier said than done and vaccination campaigns often fall short of expectations because they fail to factor in the human factor. Leveraging descriptive social norms could be a viable approach to overcome this challenge because "people like to do what most people actually do" (Thaler and Sunstein, 2008, 191). Consequently, the wise use of social nudges may be crucial to encourage employees to get a flu shot (Van Bavel et al., 2020) and to advocate vaccination among colleagues. In addition to effects on others, advocacy has proven to trigger self-persuasion, a mechanism whereby individuals who advocate for a behavior become more likely to engage in that behavior themselves (Aronson, 1999). By using the "social norm itself [as] a nudge" (Thaler and Sunstein, 2008, 259), campaigns that emphasize that most colleagues get a flu shot can induce more workers to adopt the same behavior, thus triggering a virtuous cycle.

Similar mechanisms may extend beyond vaccination to fuel other desired behaviors that public employees may otherwise engage in at suboptimal levels. In a series of meetings with over one hundred public professionals holding managerial responsibilities, asking for help from colleagues emerged as a quintessential example of this type of behavior.
Scuola Superiore Sant'Anna (Management and Healthcare Laboratory, Institute of Management and Department EMbeDS, Pisa, Italy). His research focuses on behavioral public administration and management.

Email: nicola.belle@santannapisa.it

Paola Cantarelli is an Assistant Professor at Scuola Superiore Sant'Anna (Management and Healthcare Laboratory, Institute of Management and Department EMbeDS, Pisa, Italy). Her research focuses on behavioral human resource management and work motivation in mission-driven organizations.

Email: paola.cantarelli@santannapisa.it
Public Administration Review, Vol. 81, Iss. 4, pp. 589-598. @ 2021 by The American Society for Public Administration. DOI: 10.1111/puar.13353. 
Help-seeking on the job has proven to enhance performance and nurture well-being. Indeed, the vast majority of helping behavior happens in direct response to explicit requests (Grant, 2013).

Nevertheless, public employee may tend to refrain from asking for help due to personal dilemmas and organizational practices. In this context, social nudging may come in handy to establish a norm whereby "colleagues support one another's efforts to do the best work possible" (Amabile et al., 2014, 3).

Combining insights from the focus theory of normative conduct (Cialdini et al., 1991) and nudge theory (Thaler and Sunstein, 2008), we experimentally investigate the effects of descriptive social norms on the adoption of desired behaviors among 19,984 public healthcare professionals. We do so in the context of flu vaccination and help-seeking requests, which both have ramifications for government response to public health emergencies. As to the former, we test whether public authorities may use social nudging to encourage employees to get a flu shot and advocate the same behavior among colleagues. Reaching high immunization coverage rates is crucial to build up herd immunity, which is key in the epidemic control of infectious diseases due to the positive externalities of individual vaccination (Fontanet and Cauchemez, 2020; Szucs, 2005). These externalities occur because getting a flu shot protects not only the vaccinated individual but also the community at large (Betsch et al., 2017). Furthermore, influenza vaccination has proven useful in ensuring pandemic preparedness by preserving the health and availability of healthcare workers (Prematunge et al., 2012). As to help-seeking, we test whether public organizations could leverage social norms to encourage their employees to ask for help from colleagues. This behavior may prove crucial for workers who are faced with heavy work demands, such as those health professionals must cope with during emergencies.

Our study has the potential to make several contributions to public administration theory and practice. From a theoretical perspective, we conceptualize and experimentally test on large samples of public workers the impact of social nudges on desired behaviors that employees may engage in at suboptimal levels. On the one hand, this may be a meaningful contribution to the nascent behavioral public administration literature (e.g., Battaglio Jr. et al., 2019; Grimmelikhuijsen et al., 2017). On the other hand, our work speaks to established scholarship on norm-nudging, which illuminates how the effectiveness of social norms depends on the conditional rather than unconditional nature of individual preferences (Bicchieri and Dimant, 2019). From a practical perspective, our study demonstrates that public organizations and their managers can leverage social norms to encourage conformity to desired behaviors in which employees may otherwise engage in at suboptimal levels. Methodologically, in an attempt to mitigate external validity threats that are typical of experimental work (e.g. Walker et al., 2019; Zhu et al., 2019), our research design employs a combination of large samples and replications. These procedures may inspire future work by public administrations scholars who utilize framed randomized controlled trials.

\section{Theoretical Framework and Hypotheses}

The focus theory of normative conduct (Cialdini et al., 1991) posits that different types of norms, either social or personal, influence individual behavior and illuminate the mechanisms through which those norms affect human expectations and actions. As far as social norms are concerned, Cialdini et al. (1991) distinguish between a descriptive kind and an injunctive kind. Descriptive norms are at play when individuals do what the majority of others do. Injunctive norms entail doing what the majority thinks it is right to do. Whereas descriptive norms function as a reference point toward which individuals are likely to measure the appropriateness of their conduct, injunctive norms provide a signal of what is commonly approved or disapproved in a given group. Because our aim is to investigate how public employees are influenced by the objective behavior of their colleagues, our research question only focuses on descriptive norms. As a result, our experimental design entails the manipulation of information about what colleagues do rather than about what colleagues think it is right to do.

Recent scholarship has demonstrated how social norms predictably influence individual behavior in such domains as enhancing tax compliance (e.g., Coleman, 1996; Hallsworth et al., 2017; Larkin et al., 2019), promoting the conservation of residential energy (e.g., Allcott, 2011; Cialdini and Schultz, 2004; Schultz et al., 2007) and water (Bhanot, 2018), preserving petrified woods (e.g., Cialdini et al., 2006), increasing curbside recycling (e.g., Schultz, 1999), sustaining charitable giving in wills (e.g., Behavioral Insight Team, 2013), nurturing prosocial behavior (Krupka and Weber, 2009), and reducing youth initiation to smoking (e.g., Linkenbach and Wesley Perkins, 2003). However, there is a dearth of research focused on how social norms affect public employee behavior. See for example, Hallsworth et al. (2016), where descriptive social norm feedback reduces unnecessary prescriptions for antibiotics among general practitioners in England.

In the focus theory of normative conduct, Cialdini et al. (1991) posit that norms activate conformant behaviors only when subjects' attention is focused on that norm. This resonates naturally with two behavior research streams that are theoretically robust and extensively tested in the context of empirical studies. The first area of research focuses on conformity, whereby we generally prefer to conform to the majority rather than being outcasts (e.g., Bond and Smith, 1996; Schultz et al., 2007; Thaler and Sunstein, 2008). In particular, Asch's (1956) classic studies have demonstrated that the desire to conform to the majority can lead us to change firmly held convictions, even when the majority's opinion is seemingly incorrect. The second research area focuses on the use of mechanisms through which the impact of social norms plays out, specifically availability heuristic (e.g., Kahneman, 2011; Tversky and Kahneman, 1973) and nudge theory (Thaler and Sunstein, 2008). Under System 1 thinking, thoughts that come more quickly to mind-i.e. are more readily available - tend to disproportionately influence our actions (Kahneman, 2011). Thaler and Sunstein (2008) argue that social norms have the potential for triggering availability heuristic and, thus, nudging individuals to conform to what the majority of people around them do. In their words, a "social norm [is] itself a nudge" (Thaler and Sunstein, 2008, 259). Nudges are interventions that have the potential to alter individuals' conduct "in a predictable way without forbidding any options or significantly changing their economic incentives" (Thaler and Sunstein, 2008, 6). As a consequence, choice architects, who have 
"the responsibility for organizing the context in which people make decisions" (Thaler and Sunstein, 2008, 1) can leverage social norms to nudge high-stake behaviors for the better through low-powered incentives.

Combining insights from the focus theory of normative conduct (Cialdini et al., 1991) and nudge theory (Thaler and Sunstein, 2008), we hypothesize that public employees' decisions can be causally influenced by descriptive social norms. The logic behind this expectation is that "people like to do what most people actually do" (Thaler and Sunstein, 2008, 191). Therefore, informing public employees that most of their colleagues engage in a desired behavior may nudge them to emulate the same behavior, thus triggering a virtuous cycle. Conversely, a vicious circle may occur if most colleagues abide by a conduct that makes individuals and societies worse off. We experimentally test the causal impact of descriptive social norms across different decisions-namely, getting a flu shot, advocating for vaccination, and help-seeking. The rationale behind this strategy is to strengthen the external validity of our inference. On the one hand, all three are desirable behaviors that come at personal cost. Therefore, the principles of prospect theory suggest that individuals might engage in those behaviors at suboptimal levels. This is because, due to loss aversion, people tend to prefer exposing themselves to the risk of a larger loss that is not certain rather than incurring in a sure cost (Tversky and Kahneman, 1981). Despite their similarities, our three outcome decisions differ along a relevant dimension, namely, the incentive to free ride. Whereas the individual willingness to get a flu shot might decrease as the number of colleagues who get vaccinated increases, no free-riding risk seems plausible in the case of vaccination advocacy and help-seeking. This difference provides the opportunity for an external validity test. In addition to this methodological rationale, the selection of our three behavioral outcomes was informed by a criterion of relevance for practitioners that we gauged during meetings with over one-hundred professionals.

With respect to vaccination in the workplace, the use of social nudges may be beneficial for several reasons. Firstly, descriptive norms may help public workers map their decisions into their consequences, which may be delayed and difficult to anticipate, as is the case with vaccination. Secondly, descriptive norms may be useful in correcting any lack of knowledge or misconceptions about the frequency of occurrence for a given behavior among others. Indeed, public healthcare employees may be unaware of or underestimate the vaccination coverage rate among their colleagues. Relatedly, descriptive norms may come in handy for rare decisions, such as getting a flu shot, for which public employees may be unlikely to receive the prompt feedback that would provide them with the opportunity to adjust their behavior for the better. Indeed, extant scholarship argues that social norms can promote vaccination (Brewer et al., 2017).

As for the decision to seek help on the job, the use of social nudges has the potential to shed light on the benefits of giving and receiving. Hofmann et al. (2009) define employee help-seeking as "the act of asking others for assistance, information, advice, or support" (Hofmann et al., 2009, 1262). Although making help requests on the job improves performance and nurtures well-being, the degree of help-seeking in organizations may be predictably suboptimal because individuals have a tendency to over rely on themselves, underestimate co-workers' willingness and ability to help, fear appearing incompetent, lack psychological safety, and/ or be unsure about what to request and how to ask (Baker 2020; Bamberger 2009). Medical research, in particular, has documented that overconfidence is a major factor contributing to diagnostic errors (Blumenthal-Barby and Krieger 2015; Saposnik et al. 2016) and that professionals who are excessively confident are less likely "to enlist the help of others from whose expertise they might benefit" (Cassam 2017, 3). This may be concerning because getting help from colleagues has proven effective in reducing misdiagnosis (Graber et al. 2012). Formal practices in organizations, then, may get in the way of inhibiting job-related help requests (e.g., Baker 2020; Geller and Bamberger 2012; Grant 2013). This is also problematic because the vast majority of helping behavior at work happens in direct response to explicit requests (Grant 2013). For instance, in a study with 146 nurses working in hospital settings, Hofmann et al. (2009) show that professionals were more likely to make help requests only to peers whom they perceived as accessible, trustworthy, or both. As "individuals routinely fail to seek advice" (Brooks et al. 2015, 1421), elucidating that asking colleagues for assistance is a social norm may promote help-seeking among public healthcare employees and sustain it over time in their organizations (e.g., Baker 2020; Bamberger 2009).

Based on the above premises, we formulate and test the following hypotheses:

Hypothesis 1a: A higher vaccination coverage rate among colleagues will increase public healthcare professionals' willingness to get a flu shot.

Hypothesis 1b: A higher vaccination coverage rate among colleagues will increase public healthcare professionals' willingness to advocate vaccination.

Hypothesis 2: If asking coworkers for help is the social norm rather than not, then public healthcare professionals will be more likely to make help requests.

\section{Design and Methods}

Study 1 and Study 2 are randomized controlled trials (RCTs) (Harrison and List 2004) embedded in employee viewpoint surveys that a group of regions in Italy voluntarily administer to all their healthcare workers every other year. The healthcare employee viewpoint survey is composed of a series of questions on unrelated topics regarding their job. According to the widely used experimental taxonomy proposed by Harrison and List (2004), both Study 1 and Study 2 would qualify as framed field experiments because the subject pool consists of workers, as opposed to students or MTurkers, and the task and information set includes field contexts. Subjects were recruited via email invitations and completed the experiments through Qualtrics. Participation was anonymous and voluntary. To ensure that subjects were totally blind to our research questions, respondents did not receive any prior information about the purpose of the experimental survey.

In both RCTs, we manipulate the extent to which a desired behavior is the social norm and then measure the likelihood that public 
professionals engage in that behavior. While in Study 1 we indirectly manipulate the social norm construct through the percentage of colleagues engaging in the target behavior (high vs low), in Study 2 we directly manipulate the social norm status of the target behavior (yes vs no).

Our research design accomplishes the following complementary goals. First, we employ operations that are as close as possible to the theoretical definition of social nudges in the form of descriptive norms. In other words, our work is meant to be a strong test of its theories of reference. As such, we are taking up recent calls in our discipline for testing theory by matching methods used with substantive questions (e.g., Zhu et al. 2019). Secondly, we designed a combination of randomized trials to replicate and extend our own theorizing and findings. In so doing, our study resonates with Walker et al.' (2019) conclusion that "replication should be part of the normal scientific process in public administration to help... provide valuable lessons to practice" (Walker et al. 2019, 609). Lastly, our design is meant to be in-line with insights of the EAST framework (Cabinet Office 2014). In its systematic attempt to help choice architects in public administration use behavioral insights to improve outcomes across policy domains, the United Kingdom's Behavioral Insights Team has developed a framework aimed at encouraging desired behaviors by making those "Easy, Attractive, Social and Timely" or EAST (Cabinet Office, Behavioural Insights Team 2014, 4). The framework explains that describing what most people do in a particular situation (i.e., social norms) and leveraging on the natural connections in networks and social relationships shapes actions.

\section{Study 1}

In Study 1, subjects were asked to imagine themselves working at a local health authority (LHA) and presented with a chart showing the previous year flu vaccination coverage for the assigned LHA alongside the vaccination rates in all the other LHAs within the same regional healthcare system. The assigned LHA was the one with the highest vaccination coverage (i.e. 69\%) within the region for a random half of subjects (Figure A1 of Appendix 1) and the one with the lowest vaccination rate (i.e. 13\%) for the other half of participants (Figure A2 of Appendix 1).

After being exposed to one of the two experimental treatments, all participants stated on a $0-100$ scale their probability of (i) getting a flu shot in the upcoming influenza season and (ii) encouraging coworkers to get vaccinated in the upcoming influenza season. Our two outcome variables were presented to subjects in a random sequence to avoid any ordering effect. Before terminating the survey, participants indicated their job family, the type of organization they work for, and their gender.

We employed the research design of Study 1 in three Regions. Unbeknown to subjects, the vaccination coverage figures are real data from the first Region that administered this RCT. Local health authorities' names are blinded. To test the external validity of the findings from the first trial, we replicated the same scenarios across the other two Regions.

\section{Study 2}

In Study 2, participants were prompted to imagine that they were facing a job problem and that they had to decide whether to seek help from coworkers. Before stating —on a $0-100$ point scale-the probability that they would make an help request, subjects were randomly assigned to one of two groups. Whereas a random half of the respondents read that asking colleagues for help is the norm in their organization, the other half read that asking colleagues for help is not the norm in their organization. At the end of the survey, subjects provided demographics information.

\section{Results}

\section{Study 1}

Study 1 is composed of 18,046 healthcare professionals working in three Regions in Italy, described henceforth as Regions A, B, and C, respectively. About 63 percent of the participants are employed by the healthcare system of Region A, where data were collected in March and April 2019; 2 percent of the sample are employed in Region B, where the randomized survey was administered from May through August 2019; and 35 percent of the sample are employed in Region C, where the experiment took place between mid-October and mid-November 2019. As far as job families are concerned, nurses make up about 51 percent of the sample, medical doctors 20 percent, administrative staff 12 percent, and technical personnel 10 percent. Approximately 5 percent of the sample belong to other job families and 2 percent did not indicate their job category. Nearly 56 percent of professionals work in hospitals, 25 percent in ambulatory care settings, 15 percent in teaching hospitals, 1 percent in administrative agencies, and 2 percent did not indicate the type of organization in which they are employed. As for gender, about 67 percent of respondents are female, 31 percent male, and 2 percent did not provide gender information. As expected, due to randomization, the two experimental groups in Study 1 are statistically indistinguishable based on each of these demographic characteristics.

Figure 1 displays the average probability of getting a flu shot by organizational vaccination coverage considering vaccination rates in the previous year. An analysis of variance shows that the probability of getting the flu shot is 5.52 percentage points higher among healthcare professionals randomly assigned to the condition in which most colleagues got vaccinated the previous year $(n=9.038$, $\mathrm{M}=57.23, \mathrm{SD}=40.00)$, compared to those randomly assigned to the condition in which most colleagues did not get the flu shot

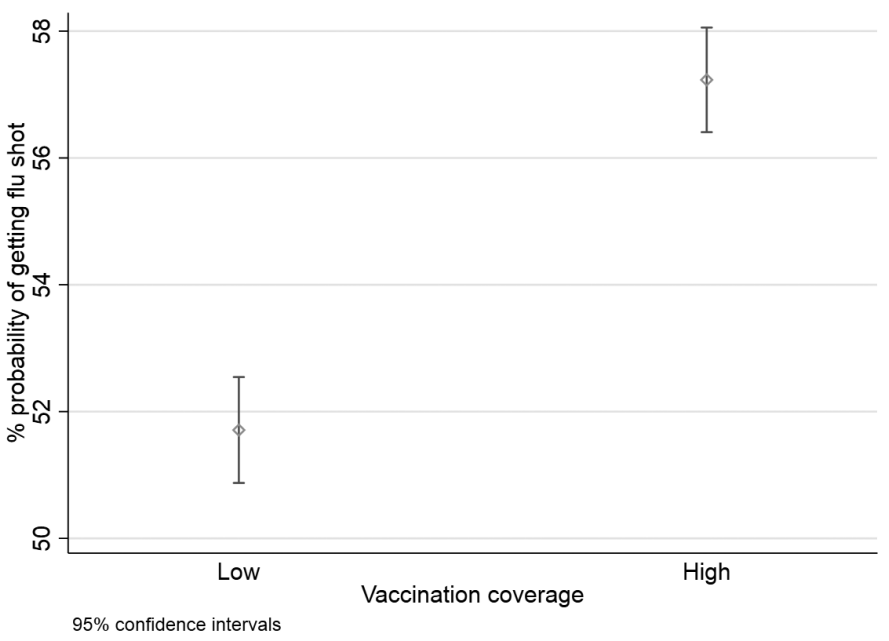

Figure 1 Average Probability of Getting the Flu Shot, by Vaccination Coverage Rates Among Colleagues (Study 1) 
the previous year $(n=9008, \mathrm{M}=51.71, \mathrm{SD}=40.44)(p<.001)$. Thus, supporting Hypothesis 1a, the high vaccination coverage manipulation-with regards to the low vaccination coverage manipulation-serves as a social nudge to enhance healthcare personnel's propensity to get the flu shot.

Figure 2 shows the results for the other outcome variable, namely, the mean probability of advocating vaccination among coworkers by experimental treatment. An analysis of variance reveals the same pattern of findings found in Figure 1. Specifically, the average probability of encouraging others to vaccinate is 6.40 percentage points greater for the random half of respondents prompted to imagine that they worked for the organization that registered the highest vaccination rate among employees in the previous year $(n=9.038, \mathrm{M}=59.58, \mathrm{SD}=37.09)$ compared to their peers asked to imagine that they worked for the organization that registered the lowest vaccination rate among employees in the previous year $(n=9008, \mathrm{M}=53.18, \mathrm{SD}=37.68)(p<.001)$. Compared to the low-vaccination coverage treatment, the high vaccination coverage treatment tends to prove effective in increasing professionals' propensity to advocate in favor of vaccination among others, thus supporting Hypothesis $1 \mathrm{~b}$.

A series of tests for the equality of means find that the probability of encouraging others to get vaccinated is higher than the probability of getting the flu shot across experimental groups. On average, the difference between the probability of advocating vaccination and the probability of getting vaccinated is +1.47 percentage points among respondents in the low vaccination coverage arm $(p=.012)$ and +2.35 percentage points for their peers in the high coverage group $(p<.001)$.

\section{Study 2}

Study 2 is composed of 1938 healthcare professionals working for Region C, the same Region C in Study 1. Data for Study 2 were collected in the second half of November 2019. Thus, while the Region of origin-C-remains the same, the specific respondents are different for Study 2. Professionals in Study 2 are distributed

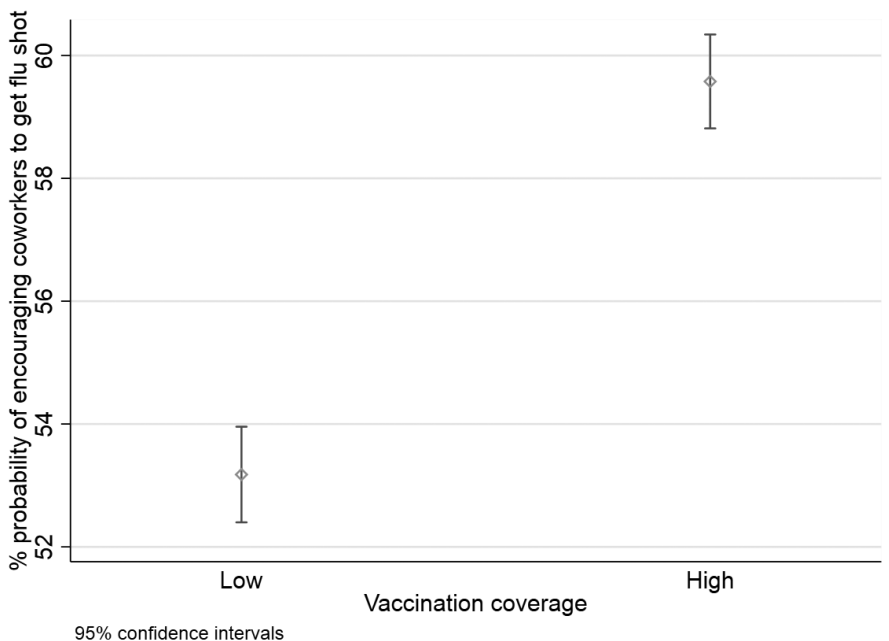

Figure 2 Average Probability of Advocating Immunization Against Seasonal Influenza in the Workplace, by Vaccination Coverage Rates Among Colleagues (Study 1) as follows in terms of job family: approximately 45 percent nurses, 21 percent medical doctors, 15 percent technicians, 11 percent administrative personnel, and 9 percent other job categories. As to organization type, about 47 percent of professionals work for hospitals, 27 percent in ambulatory care settings, 19 percent in teaching hospitals, 3 percent in administrative agencies, and the remaining 4 percent of the sample did not indicate employer organization type. The distribution of participants based on gender is as follows: about 67 percent female, 29 percent male, and 4 percent did not indicate their gender. Thanks to the randomization procedure, these characteristics do not statistically vary across experimental conditions.

Figure 3 reports the average probability that healthcare workers would make a help request based on whether asking for help in the workplace is the social norm or not. Being exposed to an environment in which making help requests to colleagues to solve job problems is normal — rather than not normal—boosts professionals' propensity to ask for help by +4.91 percentage points $(n=972, \mathrm{M}=75.99, \mathrm{SD}=24.14 ; n=966, \mathrm{M}=71.09, \mathrm{SD}=25.89$; $p<.001$ ), thus supporting Hypothesis 2. Similar to the vaccination coverage context, establishing a social norm whereby employees ask for help from colleagues when challenged by a job problem tends to be an effective nudge.

\section{Discussion}

Scholars have recently suggested that governments should invest more in nudges because their impact "is often greater, on a costadjusted basis, than that of traditional tools" (Benartzi et al. 2017, 1051). Consistent with this evidence, our experimental data suggest that social norms can be an effective nudge that has the potential to alter the behavior of public professionals for the better, without using neither financial incentives nor prohibitions.

In several framed randomized controlled trials with large samples of public healthcare professionals, we found that the probability of undertaking desired behaviors-namely, getting a flu shot, advocating for vaccination among coworkers, and help-seeking on the job-were significantly enhanced by a social norm highlighting that most colleagues engage in like behaviors. We found an opposite

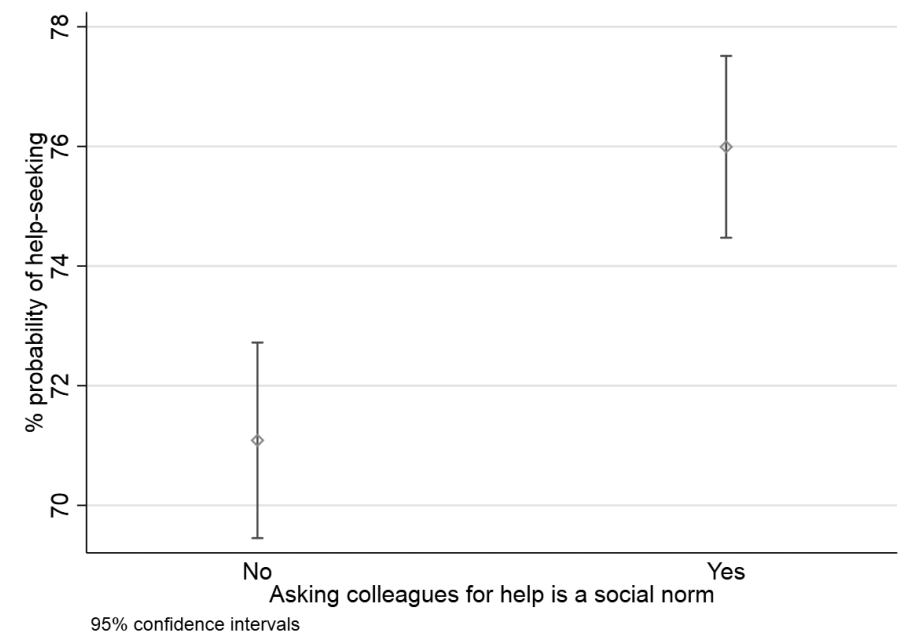

Figure 3 Average Probability of Requesting Help from Colleagues, by Social Norm (Study 2) 
pattern of results - that is, a significantly smaller willingness to get vaccinated, advocate for vaccination, and seek advice-for the random half of participants informed that most of their colleagues did not get a flu shot or that asking colleagues for help was not the norm in their organization. Our manipulations of descriptive norms serve to raise participant awareness of the prevalence of a certain conduct so as to make that conduct easily available in their minds, thus becoming prominent and salient. Leveraging the focus theory of normative conduct (Cialdini et al. 1991) and nudge theory (Thaler and Sunstein 2008), our studies promote a deeper understanding of how public employees' behavior can be altered for better by employing social influences rather than mandates or incentives. Indeed, van Bavel et al. (2020) argue that a "way to leverage the impact of norms falls under the general category of 'nudges', which influence behaviour through modification of choice architecture" (463). In line with Thaler and Sunstein's (2008) consideration that "if choice architects want to shift behavior and to do so with a nudge, they might simply inform people about what other people are doing" (Thaler and Sunstein 2008, 71), we tested interventions in two areas where the use of mandates or incentives is typically limited or problematic, namely, vaccination and help-seeking.

The positive relationship between the vaccination coverage rate among their colleagues and the individual propensity of employees to get vaccinated that we observed in our experimental setting is even more promising in light of potential free riding. This should increase with the number of colleagues who get the flu shot, thus making it less likely for any given individual to get infected due to the positive externalities of vaccination. In other words, the free riding and the social norm effects should work in opposite directions, thus potentially canceling each other out. In this respect, the results of our experimental test of the social norming effect can be considered conservative because we do observe a significant increase in the probability of getting a flu vaccination as the number of vaccinated colleagues goes up, notwithstanding possible incentives to free ride.

Our study may provide a test of the double-sided nature of social norms in the workplace, thus, demonstrating that "governments can use the power of social influence to promote many good (and bad) causes" (Thaler and Sunstein 2008, p. 78). More precisely, we show that descriptive norms are so contagious among public employees that they can trigger and nurture both virtuous and vicious cycles, depending on whether the majority of colleagues conform to a positive behavior or a negative conduct, respectively. While previous scholarship mostly compared the effectiveness of different types of norms or different formats for the same kind of norm (Cialdini and Schultz 2004; Hallsworth et al. 2017), our manipulations of descriptive norms might warn choice architects in public administration about the use of social nudges when the prevalence of good behaviors is low.

Our theorizing and results provide valuable insights toward the emerging focus on behavioral public administration in our discipline (e.g., Battaglio Jr. et al. 2019; Grimmelikhuijsen et al. 2017).

Specifically, we focus on the use of nudging among public employees and the impact on the collective greater good. In contrast, most behavioral public administration literature conducts research on samples of citizens in non-organizational settings (e.g., Baekgaard and Serritzlew 2016; Barrows et al. 2016; Jilke et al. 2016;
Linos 2018; Linos et al. 2020; Marvel 2016; Olsen 2017). Our work joins recent efforts (e.g., Belle et al. 2017, 2018, 2019; Cantarelli et al. 2020; Meier et al. 2015; Nagtegaal et al. 2019) in speaking to choice architects who intend to nudge desirable behaviors in which public employees may engage in at suboptimal levels.

Methodologically, we demonstrate the benefits of replicating the same design and methods across samples, settings, and operations to test the external validity of our findings (Shadish et al. 2002). Heeding the call for greater replication in public administration research (e.g., George et al. 2017; Levitt and List 2007; Walker et al. 2017, 2019), the framed randomized controlled trials reported in our study consistently demonstrate that the effect of descriptive social norms holds across large-scale samples of public employees, regional healthcare systems, outcome variables, and operationalization of the factor variable.

Another methodological contribution of our work lies in showing the potential for the use of true and desirable social norms as a means for inducing positive behaviors. The force and form of the social norms effect "can only be soundly established through theoretical refinements that have not been traditionally or rigorously applied" (Cialdini et al. 1991, 202). We strictly operationalize the theoretical definition of descriptive norms concerning the focus theory of normative conduct. Moreover, our descriptive norms operations are in line with the EAST framework, which suggests most people perform a desired behavior or use the power of networks to foster mutual support (Cabinet Office 2014).

Finally, we contribute to understanding the impact of social norms on vaccination programs (e.g. Van Bavel et al. 2020; Chen and Stevens 2017; Corace et al. 2016; Dempsey et al. 2018; Ng et al. 2020). Within this scholarship, "few randomized trials have tested strategies to change social processes to increase vaccination uptake" (Brewer et al. 2017, 149). Likewise, our findings advance research into help-seeking behavior as a buffer to cope with work demands in stressful professional environments such as public healthcare (e.g., Baker 2020; Brooks et al. 2015; Geller and Bamberger 2012). Our results may have currency at times when governments across the globe are navigating a pandemic crisis. On the one hand, encouraging help-seeking is crucial to reducing burnout among public professionals confronted with unprecedented work demands. On the other hand, as COVID-19 vaccines become available, maximizing immunization rates will be crucial to prevent future waves of coronavirus cases.

\section{Limitations}

Our results should be interpreted considering several limitations, which offer avenues for future research. First and foremost, the outcome in our randomized experiments is self-reported behavior. As a result, the dependent variables measure stated intentions rather than revealed preferences, which can only be observed through actual behavior. This may have ramifications in terms of the external validity of our inference. For instance, the degree to which stated intentions to get a flu shot translate into actual vaccination remains to be seen. This concern is partially mitigated by evidence suggesting that "vaccination intention was the strongest predictor of subsequent vaccination, explaining over $60 \%$ of the seasonal influenza vaccination uptake among healthcare professionals" (Ng et al. 2020, 695). Nevertheless, future 
field experiments are certainly needed that test the generalizability of our findings beyond our artificial setting to more naturally occurring environments. Another potential threat to the external validity of our inference lies in the generalizability of results to other categories of public sector workers. This concern is partially mitigated by the heterogeneity of our pool of subjects, which includes clinical, technical, and administrative workers.

An additional limitation of our study lies in the selection of the outcome behaviors targeted by our experimental manipulations of social norms. Different selection criteria may have been equally relevant and could have led to the study of other decision domains. Future research is certainly needed that replicates our experimental design using different behavioral outcomes. This would allow identifying typologies of behaviors for which social nudging may be more or less effective.

Moreover, despite being "the most efficient tool that researchers and program evaluators have at their disposal to obtain an unbiased estimate of the average effect caused by an intervention of some kind" (Belle and Cantarelli 2018, p. 496), randomized experiments are unable to show the mechanisms through which that effect plays out. Whereas we can claim that our experimental manipulations of descriptive social norms have a causal impact on self-reported intentions to behave, the chain reaction leading from manipulations to outcomes remains a black box. Our design does not allow unpacking the mechanisms that concur to the overall treatment effect. These might include, for instance, availability heuristic (e.g. Cialdini et al. 1991), demand effect (Zizzo 2010), priming, self-concept maintenance (Mazar et al. 2008), and free-riding. Most notably, our study is unable to single out the opposite effects of free riding, which can increase with the number of colleagues already vaccinated (Betsch et al. 2017), and social norms in vaccination decisions. Other research designs - for instance parallel designs (Imai et al. 2013), mixed-methods studies (e.g., Mele and Belardinelli 2019), and qualitative inquiries (e.g., Ashworth et al. 2019) —are superior in addressing such questions. Subsequently, such designs could test the hypothesis that social nudges affect behaviors through the availability heuristic (e.g., Cialdini et al. 1991).

Another limitation of our study, which points toward future directions, lies in exclusively focusing on descriptive norms, thus leaving out other constructs that have been investigated in related areas. In particular, extensions of our research design might pursue greater integration with the well-established scholarship on normnudging, which lies at the intersection of economics and political science and provides valuable insights into the risks and benefits of social information (Bicchieri and Dimant 2019). Moreover, future experimental work might target the manipulation of injunctive norms in addition to descriptive norms (Cialdini et al. 1991) or include less extreme treatment levels that are less spaced out from each other so as to alleviate the risk of priming. More in general, future work may broaden the scope of our project by exploring the relative impact that organizational and logistical factors may have on vaccination decisions and help seeking at work.

\section{Conclusion}

Scholars have recently called for the use of behavioral science as a means for interventions that leverage the impact of social norms for an effective response to the COVID-19 pandemic (Van Bavel et al. 2020).
The insights from our behavioral research are salient given the world fight against the spread of coronavirus (SARS-CoV-2) — a virus that "is more powerful in creating political, economic and social upheaval than any terrorist attack" (Nebehay and Farge 2020). As healthcare providers move to the next stage of vaccination in the COVID-19 battle, they will need to do so in a manner that protects public employees and patients alike. The use of "social nudges as choice architecture" (Thaler and Sunstein 2008, 71) may prove essential to ensuring the safety and well-being of public healthcare employees.

\section{References}

Allcott, Hunt. 2011. "Social Norms and Energy Conservation." Journal of Public Economics 95(9-10): 1082-95.

Amabile, Teresa, Colin M. Fisher, and Julianna Pillemer. 2014. "IDEO’s Culture of Helping." Harvard Business Review 92(1): 54-61.

Aronson, Elliot. 1999. "The Power of Self-Persuasion.” American Psychologist 54(11): 875-84.

Asch, Solomon E. 1956. "Studies of Independence and Conformity: A Minority of One against a Unanimous Majority." Psychological Monographs: General and Applied 70(9): 1-70.

Ashworth, Rachel Elizabeth, Aoife Mary McDermott, and Graeme Currie. 2019. "Theorizing from Qualitative Research in Public Administration: Plurality through a Combination of Rigor and Richness." Journal of Public Administration Research and Theory 29(2): 318-33.

Baekgaard, Martin, and Søren Serritzlew. 2016. "Interpreting Performance Information: Motivated Reasoning or Unbiased Comprehension.” Public Administration Review 76(1): 73-82.

Baker, Wayne. 2020. All You Have to Do Is Ask. How to Master the most Important Skill for Success. New York: Penguin Random House LLC.

Bamberger, Peter. 2009. "Employee Help-Seeking: Antecedents, Consequences and New Insights for Future Research." Research in Personnel and Human Resources Management 28(1): 49-98.

Banerjee, Abhijit Vinayak, Esther Duflo, Rachel Glennerster, and Dhruva Kothari. 2010. "Improving Immunisation Coverage in Rural India: Clustered Randomised Controlled Evaluation of Immunisation Campaigns with and without Incentives." BMJ 340: c2220.

Barrows, Samuel, Margaret Henderson, Paul E. Peterson, and Martin R. West. 2016. "Relative Performance Information and Perceptions of Public Service Quality: Evidence from American School Districts." Journal of Public Administration Research and Theory 26(3): 571-83.

Battaglio, R. Paul, Jr., Paolo Belardinelli, Nicola Belle, and Paola Cantarelli. 2019. "Behavioral Public Administration ad fontes: A Synthesis of Research on Bounded Rationality, Cognitive Biases, and Nudging in Public Organizations." Public Administration Review 79(3): 304-20.

Behavioural Insights Team. 2013. Applying Behavioural Insights to Charitable Giving. Cabinet Office.

Belle, Nicola, and Paola Cantarelli. 2018. "Randomized Experiments and Reality of Public and Nonprofit Organizations: Understanding and Bridging the Gap." Review of Public Personnel Administration 38(4): 494-511.

Belle, Nicola, Paola Cantarelli, and Paolo Belardinelli. 2017. "Cognitive Biases in Performance Appraisal: Experimental Evidence on Anchoring and Halo Effects with Public Sector Managers and Employees." Review of Public Personnel Administration 37(3): 275-94.

_ 2018. "Prospect Theory Goes Public: Experimental Evidence on Cognitive Biases in Public Policy and Management Decisions.” Public Administration Review 78(6): 828-40.

Belle, Nicola, Paolo Belardinelli, Paola Cantarelli, and Valentina Mele. 2019.

"On Iron Cages and Suboptimal Choices: An Experimental Test of the 
Micro-Foundations of Isomorphism in the Public Sector." International Public Management Journal 22(2): 373-414.

Benartzi, Shlomo, John Beshears, Katherine L. Milkman, Cass R. Sunstein, Richard H. Thaler, Maya Shankar, Will Tucker-Ray, William J. Congdon, and Steven Galing. 2017. "Should Governments Invest More in Nudging?” Psychological Science 28(8): 1041-55.

Betsch, Cornelia, Robert Böhm, Lars Korn, and Cindy Holtmann. 2017. "On the Benefits of Explaining Herd Immunity in Vaccine Advocacy." Nature Human Behaviour 1(3): 1-6.

Bhanot, Syon P. 2018. "Isolating the Effect of Injunctive Norms on Conservation Behavior: New Evidence from a Field Experiment in California." Organizational Behavior and Human Decision Processes In press. https://doi.org/10.1016/j.obhdp. 2018.11.002

Bicchieri, Cristina, and Eugen Dimant. 2019. "Nudging with Care: The Risks and Benefits of Social Information.” Public Choice : 1-22. https://doi.org/10.1007/ s11127-019-00684-6.

Blumenthal-Barby J. S., and Heather Krieger. 2015. "Cognitive Biases and Heuristics in Medical Decision Making: A Critical Review Using a Systematic Search Strategy." Medical Decision Making 35(4): 539-57.

Bond, Rod, and Peter B. Smith. 1996. "Culture and Conformity: A Meta-Analysis of Studies Using Asch's (1952b, 1956) Line Judgment Task.” Psychological Bulletin 119(1): 111-37.

Brewer, Noel T., Gretchen B. Chapman, Alexander J. Rothman, Julie Leask, and Allison Kempe. 2017. "Increasing Vaccination: Putting Psychological Science into Action." Psychological Science in the Public Interest 18(3): 149-207.

Brooks, Alison Wood, Francesca Gino, and Maurice E. Schweitzer. 2015. "Smart People Ask for (my) Advice: Seeking Advice Boosts Perceptions of Competence." Management Science 61(6): 1421-35.

Cabinet Office, Behavioural Insights Team. 2014. EAST: Four Simple Ways to Apply Behavioural Insights, http://38r8om2xjhhl25mw24492dir.wpengine.netdnacdn.com/wp-content/uploads/2015/07/BIT-Publication-EAST_FA_WEB.pdf [accessed March 2020].

Cantarelli, Paola, Nicola Belle, and Paolo Belardinelli. 2020. "Behavioral Public HR: Experimental Evidence on Cognitive Biases and Debiasing Interventions." Review of Public Personnel Administration 40(1): 56-81.

Cassam, Quassim. 2017. "Diagnostic Error, Overconfidence and Self-Knowledge." Palgrave Communications 3(1): 1-8.

Chen, F., and R. Stevens. 2017. "Applying Lessons from Behavioral Economics to Increase Flu Vaccination Rates.” Health Promotion International 32(6): 1067-73.

Cialdini, Robert, and Weseley P. Schultz. 2004. Understanding and Motivating Energy Conservation Via Social Norms 1-6. William and Flora Hewlett Foundation.

Cialdini, Robert B., Carl A. Kallgren, and Raymond R. Reno. 1991. “A Focus Theory of Normative Conduct: A Theoretical Refinement and Reevaluation of the Role of Norms in Human Behavior." In Advances in Experimental Social Psychology, Vol 24 201-34. Cambridge, MA: Academic Press.

Cialdini, Robert B., Linda J. Demaine, Brad J. Sagarin, Daniel W. Barrett, Rhoads Kelotn, and Patricia L. Winter. 2006. "Managing Social Norms for Persuasive Impact." Social Influence 1(1): 3-15.

Coleman, Stephen. 1996. The Minnesota Income Tax Compliance Experiment. St. Paul, MN: Minnesota Department of Revenue.

Corace, Kimberly M., Jocelyn A. Srigley, Daniel P. Hargadon, Dorothy Yu, Tara K. MacDonald, Leandre R. Fabrigar, and Gary E. Garber. 2016. "Using Behavior Change Frameworks to Improve Healthcare Worker Influenza Vaccination Rates: A Systematic Review." Vaccine 34(28): 3235-42.

Dempsey, Robert C., John McAlaney, and Bridgette M. Bewick. 2018. "A Critical Appraisal of the Social Norms Approach as an Interventional Strategy for Health-Related Behavior and Attitude Change." Frontiers in Psychology 9: 2180. https://doi.org/10.3389/fpsyg.2018.02180
Fontanet, Arnaud, and Simon Cauchemez. 2020. "COVID-19 Herd Immunity: Where Are we?” Nature Reviews Immunology 20(10): 583-4.

Geller, Dvora, and Peter A. Bamberger. 2012. "The Impact of Help Seeking on Individual Task Performance: The Moderating Effect of Help seekers' Logics of Action." Journal of Applied Psychology 97(2): 487-97.

George, Bert, Sebastian Desmidt, Paul A. Nielsen, and Martin Baekgaard. 2017. "Rational Planning and politicians' Preferences for Spending and Reform: Replication and Extension of a Survey Experiment." Public Management Review 19(9): 1251-71.

Graber, Mark L., Stephanie Kissam, Velma L. Payne, Ashley N.D. Meyer, Asta Sorensen, Nancy Lenfestey, Elizabeth Tant, Kerm Henriksen, Kenneth LaBresh, and Hardeep Singh. 2012. "Cognitive Interventions to Reduce Diagnostic Error: A Narrative Review.” BMJ Quality \& Safety 21(7): 535-57.

Grant, Adam M. 2013. Give and Take: A Revolutionary Approach to Success. New York, NY: Penguin.

Grimmelikhuijsen, Stephan, Sebastian Jilke, Asmus L. Olsen, and Lars Tummers. 2017. "Behavioral Public Administration: Combining Insights from Public Administration and Psychology." Public Administration Review 77(1): 45-56.

Hallsworth, Michael, Tim Chadborn, Anna Sallis, Michael Sanders, Daniel Berry, Felix Greaves, Lara Clements, and Sally C. Davies. 2016. "Provision of Social Norm Feedback to High Prescribers of Antibiotics in General Practice: A Pragmatic National Randomised Controlled Trial.” The Lancet 387(10029): 1743-52.

Hallsworth, Michael, John A. List, Robert D. Metcalfe, and Ivo Vlaev. 2017. “The Behavioralist as Tax Collector: Using Natural Field Experiments to Enhance Tax Compliance." Journal of Public Economics 148: 14-31.

Harrison, Glenn W., and John A. List. 2004. "Field Experiments." Journal of Economic Literature 42(4): 1009-55.

Hofmann, David A., Zhike Lei, and Adam Grant. 2009. "Seeking Help in the Shadow of Doubt: The Sensemaking Processes Underlying how Nurses Decide Who to Ask for Advice." Journal of Applied Psychology 94(5): 1261-74.

Imai, Kosuke, Dustin Tingley, and Teppei Yamamoto. 2013. "Experimental Designs for Identifying Causal Mechanisms." Journal of the Royal Statistical Society: Series A (Statistics in Society) 176(1): 5-51.

Jilke, Sebastian, Gregg G. Van Ryzin, and Steven Van de Walle. 2016. "Responses to Decline in Marketized Public Services: An Experimental Evaluation of Choice Overload." Journal of Public Administration Research and Theory 26(3): 421-32.

Kahneman, Daniel. 2011. Thinking, Fast and Slow. New York, NY: Routledge.

Krupka, Erin, and Roberto A. Weber. 2009. "The Focusing and Informational Effects of Norms on pro-Social Behavior." Journal of Economic Psychology 30(3): 307-20.

Larkin, Chris, Michael Sanders, Isabelle Andresen, and Felicity Algate. 2019.

"Testing Local Descriptive Norms and Salience of Enforcement Action: A Field Experiment to Increase Tax Collection." Journal of Behavioral Public Administration 2(1): 1-11.

Levitt, Steven D., and John A. List. 2007. "What Do Laboratory Experiments Measuring Social Preferences Reveal about the Real World?" The Journal of Economic Perspectives 21: 153-74.

Linkenbach, Jeffrey W., and H. Wesley Perkins. 2003. "MOST of us Are Tobacco Free: An Eight-Month Social Norms Campaign Reducing Youth Initiation of Smoking in Montana." In The Social Norms Approach to Preventing School and College Age Substance Abuse: A Handbook for Educators, Counselors, and Clinicians, edited by H.W. Perkins, 224-34. San Francisco, CA: Jossey-Bass.

Linos, Elizabeth. 2018. "More than Public Service: A Field Experiment on Job Advertisements and Diversity in the Police." Journal of Public Administration Research and Theory 28(1): 67-85.

Linos, Elizabeth, Lisa T. Quan, and Elspeth Kirkman. 2020. "Nudging Early Reduces Administrative Burden: Three Field Experiments to Improve Code Enforcement." Journal of Policy Analysis and Management 39(1): 243-65.

Marvel, John.D. 2016. "Unconscious Bias in Citizens' Evaluations of Public Sector Performance." Journal of Public Administration Research and Theory 26(1): 143-58. 
Mazar, Nina, On Amir, and Dan Ariely. 2008. "The Dishonesty of Honest People: A

Theory of Self-Concept Maintenance." Journal of Marketing Research 45(6): 633-44.

Meier, Kenneth J., Søren C. Winter, Laurence J. O’Toole, Nathan Favero, and Simon

C. Andersen. 2015. "The Validity of Subjective Performance Measures: School

Principals in Texas and Denmark." Public Administration 93(4): 1084-101.

Mele, Valentina, and Paolo Belardinelli. 2019. "Mixed Methods in Public

Administration Research: Selecting, Sequencing, and Connecting." Journal of

Public Administration Research and Theory 29(2): 334-47.

Nagtegaal, R., L. Tummers, M. Noordegraaf, and V. Bekkers. 2019. "Nudging

Healthcare Professionals towards Evidence-Based Medicine: A Systematic

Scoping Review." Journal of Behavioral Public Administration 2(2): 1-20.

Nebehay, Stephanie, and Emma Farge. 2020. "Coronavirus Emergency Is 'Public

Enemy Number 1': WHO.” Reuters https://www.reuters.com/article/us-Chinahealth-who/coronavirus-emergency-holds-a-very-grave-threat-for-world-whoidUSKBN2050YV [accessed March 23, 2020]

Ng, Tiffany W.Y., Benjamin J. Cowling, Hau Chi So, Dennis K.M. Ip, and Qiuyan Liao. 2020. "Testing an Integrative Theory of Health Behavioural Change for Predicting Seasonal Influenza Vaccination Uptake among Healthcare Workers.” Vaccine 38(3): 690-8.

Olsen, Asmus.L. 2017. "Human Interest or Hard Numbers? Experiments on Citizens' Selection, Exposure, and Recall of Performance Information." Public Administration Review 77(3): 408-20.

Organization for Economic Co-operation and Development. 2019. Health at a Glance 2019: OECD Indicators. Paris: OECD Publishing.

Prematunge, Chatura, Kimberly Corace, Anne McCarthy, Rama C. Nair, Renee Pugsley, and Gary Garber. 2012. "Factors Influencing Pandemic Influenza Vaccination of Healthcare Workers-A Systematic Review." Vaccine 30(32): 4733-43.

Saposnik, Gustavo, Donald Redelmeier, Christian C. Ruff, and Philippe N. Tobler. 2016. "Cognitive Biases Associated with Medical Decisions: A Systematic Review." BMC Medical Informatics and Decision Making 16(1): 138.

Schultz, Weseley P. 1999. "Changing Behavior with Normative Feedback Interventions: A Field Experiment on Curbside Recycling.” Basic and Applied Social Psychology 21(1): 25-36.
Schultz, Weseley P., Jessica M. Nolan, Robert B. Cialdini, Noah J. Goldstein, and Vladas Griskevicius. 2007. "The Constructive, Destructive, and Reconstructive Power of Social Norms." Psychological Science 18(5): 429-34.

Shadish, William R., Thomas D. Cook, and Donald T. Campbell. 2002. Experimental and Quasi-Experimental Designs for Generalized Causal Inference. Boston: Houghton Mifflin.

Szucs, Thomas D. 2005. "Health Economic Research on Vaccinations and Immunisation Practices-An Introductory Primer." Vaccine 23(17-18): 2095-103.

Thaler, Richard H., and Cass R. Sunstein. 2008. Nudge: Improving Decisions about Health, Wealth, and Happiness. New Heaven, CT: Yale University Press.

Tversky, Amos, and Daniel Kahneman. 1973. "Availability: A Heuristic for Judging Frequency and Probability." Cognitive Psychology 5: 207-32.

- 1981. "The Framing of Decisions and the Psychology of Choice." Science 211(4481): 453-8.

Van Bavel, Jay.J., Katherine Baicker, Paulo S. Boggio, Valerio Capraro, Aleksandra Cichocka, Mina Cikara, Molly J. Crockett, et al. 2020. "Using Social and Behavioural Science to Support COVID-19 Pandemic Response." Nature Human Behaviour 4: 460-71.

Walker, Richard M., Oliver James, and Gene A. Brewer. 2017. "Replication, Experiments and Knowledge in Public Management Research." Public Management Review 19(9): 1221-34.

Walker, Richard M., Gene A. Brewer, M. Jin Lee, Nicolai Petrovsky, and Arjen Van Witteloostuijn. 2019. "Best Practice Recommendations for Replicating Experiments in Public Administration." Journal of Public Administration Research and Theory 29(4): 609-26.

World Health Organization. 2012. Vaccines against Influenza WHO Position Paper.

Zhu, Ling, Christopher Witko, and Kenneth J. Meier. 2019. “The Public Administration Manifesto II: Matching Methods to Theory and Substance." Journal of Public Administration Research and Theory 29(2): 287-98.

Zizzo, Daniel.J. 2010. "Experimenter Demand Effects in Economic Experiments." Experimental Economics 13(1): 75-98.

\section{APPENDIX 1}

The chart below shows the percentage of employees who vaccinated against the seasonal flu last year for each of the organizations in your regional healthcare system. Each bar represents one organization. Imagine that you work for the organization highlighted in blue in the chart below.

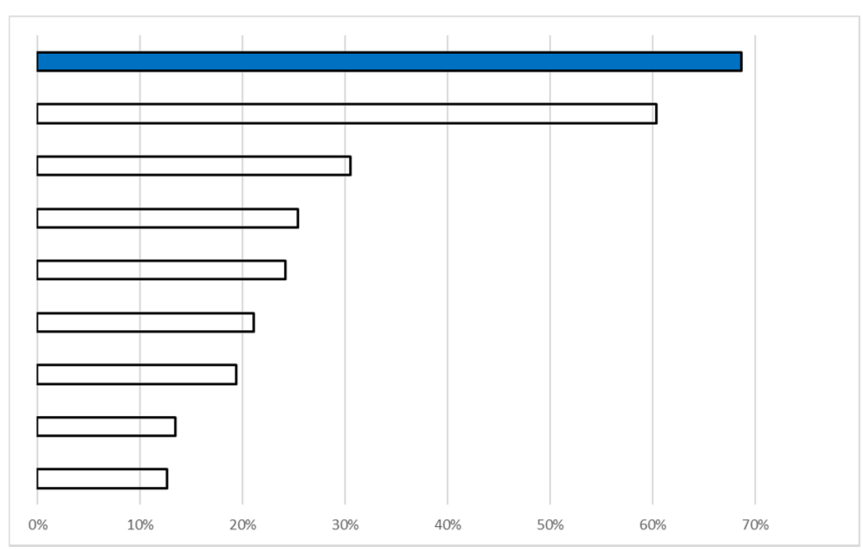

What is the probability that you will vaccinate against the seasonal flu next year?

What is the probability that you will encourage co-workers to vaccinate against the seasonal flu next year?

\section{Figure A1 High Vaccination Coverage Scenario in Study 1}


The chart below shows the percentage of employees who vaccinated against the seasonal flu last year for each of the organizations in your regional healthcare system. Each bar represents one organization. Imagine that you work for the organization highlighted in blue in the chart below.

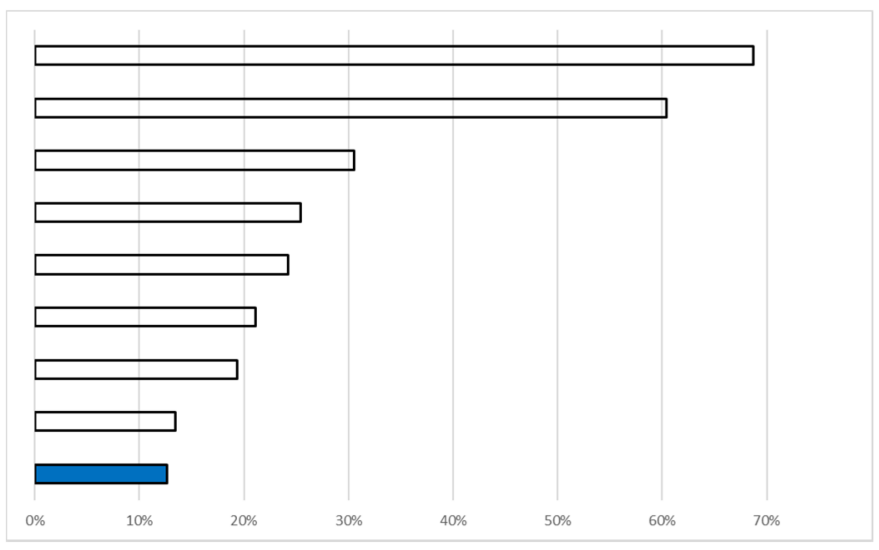

What is the probability that you will vaccinate against the seasonal flu next year?

What is the probability that you will encourage co-workers to vaccinate against the seasonal flu next year?

Figure A2 Low Vaccination Coverage Scenario in Study 1 